\title{
Análisis morfológico y contextual de las pinturas rupestres antropomorfas de la isla de Gran Canaria
}

\section{Morphological and contextual analysis of the anthropomorphic rupestrial paintings of Gran Canaria Island}

\author{
PEdRo J. SosA-Alonso \\ Departamento de Ciencias Históricas \\ Universidad de Las Palmas de Gran Canaria \\ Calle Pérez del Toro, $\mathrm{n}^{\circ}$ 1. Las Palmas de Gran Canaria \\ pedro.sosa.ae@gmail.com \\ https://orcid.org/0000-0003-0174-2594
}

\begin{abstract}
Resumen
En el presente trabajo mostramos una reflexión y análisis de las pinturas rupestres de figuras antropomorfas realizadas en las estaciones rupestres de Gran Canaria. Estos motivos representados en la roca se distribuyen en tres yacimientos arqueológicos de la isla: Majada Alta, Cuevas de Cubas y Cueva del Moro; espacios en los que hemos trabajado con técnicas de documentación no invasivas que nos han ayudado a conseguir los primeros calcos digitales de los pigmentos que se conservan en sus soportes. Este estudio ha sido necesario para conocer la verdadera morfología de los pigmentos conservados, lo que nos ha ayudado a comprender que los antropomorfos de cada yacimiento son diferentes entre sí, que no existe un estilo y que cada estación de pinturas se encuentra en un contexto diferente. Se trata de datos interesantes, pues reflejan la complejidad a la que nos enfrentamos a la hora de realizar vínculos entre las diferentes figuras humanas representadas, cuyo significado, cronologías y motivaciones no tienen por qué ser las mismas.
\end{abstract}

Palabras clave: arte rupestre, figuras humanas, pigmento rojo, arqueología canaria

\section{Abstract}

In the present work we show a reflection and analysis of the cave paintings of anthropomorphic figures made in the rock art places of Gran Canaria. These motifs represented in the rock are distributed in three archaeological sites on the island: Majada Alta, Cuevas de Cubas and Cueva del Moro. Spaces in which we have worked with non-invasive documentation techniques that have helped us to achieve the first digital traces of the pigments that are preserved in their supports. This study has been necessary to know the true morphology of the preserved pigments, which has helped us to understand that the anthropomorphs of each site are different from each other, that there is no style and that each painting station is in a different context. This is interesting data, as it reflects the complexity we face when making links between the different human figures represented, whose meaning, chronologies and motivations do not have to be the same.

Key words: Rock art, human figures, red pigment, Canarian archaeology 


\section{Introducción ${ }^{1}$}

Las poblaciones indígenas de Canarias, a partir del momento en que llegaron a las islas desde el continente africano, fueron desarrollando culturas propias desde el aislamiento que supone vivir en un contexto insular y con apenas contacto con el exterior. Aunque el sustrato base de los primeros habitantes de las islas fuese el mismo, son bastante evidentes las diferencias que existen en las distintas culturas materiales que reflejan el desarrollo de un modelo adaptativo para vivir en cada entorno de las diferentes islas. Encontramos diferencias en los espacios de hábitat, en la forma de dar sepultura a los difuntos, en la morfología de las piezas cerámicas y un largo etcétera. Sin embargo, uno de los aspectos que más destaca de cada contexto insular es el arte rupestre.

La isla de Gran Canaria destaca sobre las demás en cuanto a las manifestaciones artísticas; ejemplo de ello es el enorme repertorio rupestre que se distribuye por toda la geografía insular. La mayoría de los motivos ejecutados en las rocas por los nativos han sido en forma de petroglifos al aire libre, entre los que destacan las representaciones humanas, los grabados alfabéticos con escritura líbico-bereber y las figuras geométricas. Existen también grabados en el interior de cuevas artificiales, como los conocidos triángulos invertidos o triángulos púbicos. Pero uno de los elementos más destacados en la historia prehispánica de esta isla es la presencia de pinturas rupestres en cuevas y abrigos. La pintura está muy presente en el repertorio patrimonial de la isla, la tenemos en las cerámicas, en la estatuaria figurativa en terracota y en las paredes rocosas. En estas últimas, debemos hacer una diferencia entre la pintura mural, que se encuentra en las paredes y suelos de las estructuras de piedra y cuevas artificiales, y la pintura con motivos representados.

1 Trabajo cofinanciado por la Agencia Canaria de Investigación, Innovación y Sociedad de la Información de la Consejería de Economía, Industria, Comercio y Conocimiento y por el Fondo Social Europeo (FSE) Programa Operativo Integrado de Canarias 20I4-2020, Eje 3 Tema Prioritario 74 ( $85 \%)$.
Entre los motivos pintados, que no son tan abundantes como los grabados, tenemos de varios tipos. Entre ellos se encuentran, por un lado, los motivos geométricos. Ejemplo de ello son la Cueva Pintada de Gáldar, que da nombre al parque arqueológico más importante del archipiélago, o la cueva de Morros de Ávila, localizada en la montaña de Agüimes en la que destacan triángulos invertidos de color blanco sobre fondo rojo. Sin embargo, existen otro tipo de motivos distribuidos en diferentes zonas de la isla como los antropomorfos y los puntos en las paredes de algunas cuevas (como la Cueva de Las Estrellas en Artenara o la Cueva Pintada de Rosiana en Santa Lucía de Tirajana), entre otros. En cambio, los antropomorfos, motivos que son objeto del presente trabajo, han sido muy poco estudiados por los investigadores durante los últimos años, razón por la que consideramos imprescindible extraer información de estos enclaves arqueológicos con las técnicas de documentación, registro y análisis actuales.

Los únicos yacimientos rupestres con figuras humanas pintadas son el abrigo de Majada Alta (Tejeda), el abrigo de Cuevas de Cubas (Telde) y la Cueva del Moro (Agaete) (figura I). No descartamos que puedan aparecer en futuras prospecciones más representaciones de este tipo, pero de momento este análisis recopila el total de pinturas antropomorfas de Gran Canaria conocidas por el momento.

\section{Antecedentes y estado de la cuestión}

La primera constatación de grabados rupestres en el archipiélago canario tiene lugar en el año 1752 en la isla de La Palma, concretamente en lo que se conoce como la Cueva de Belmaco (Nougués Secall, 1858: 155; Hernández Pérez, 1996: 26). En la isla de Gran Canaria, el primer hallazgo de este tipo no se produce hasta finales del siglo xIx, con el descubrimiento de los grabados del Barranco de Balos (Agüimes), atribuido a Diego Ripoche (Grau-Bassas, I882), momento en el que se aprovechó también para publicar los primeros calcos enfocados en las inscripciones alfabéticas (Verneau, I882: 287). Sin embargo, en lo que respecta a las pinturas, la Cueva Pintada de Gáldar fue descubierta unos años antes, ya que 


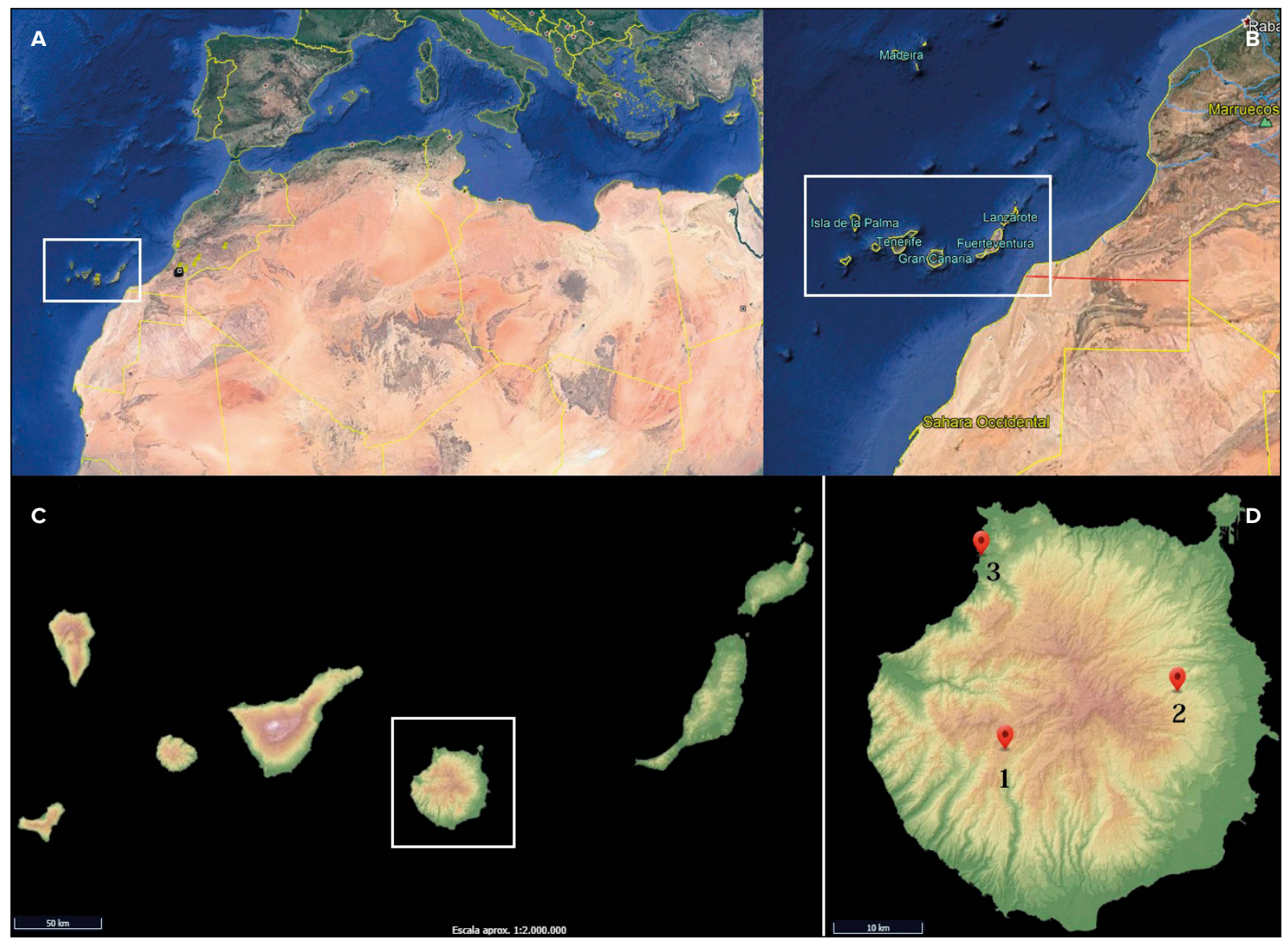

Figura 1. A. Islas Canarias en el contexto Atlántico (Google Earth Pro). B. Islas Canarias en el contexto norteafricano (Google Earth Pro). C. Localización de la isla de Gran Canaria (Sistema de Información Territorial de Canarias - IDECanarias). D. Localización de los yacimientos rupestres con pinturas antropomorfas: 1. Majada Alta; 2. Cuevas de Cubas y 3. Cueva del Moro (Sistema de Información Territorial de Canarias - IDECanarias)

Figure 1. A. Canary Islands in the Atlantic context (Google Earth Pro). B. Canary Islands in the North African context (Google Earth Pro). C. Location of the island of Gran Canaria (Canary Islands Territorial Information System - IDECanarias). D. Location of cave sites with anthropomorphic paintings: 1. Majada Alta; 2. Cuevas de Cubas and 3. Cueva del Moro (Territorial Information System of the Canary Islands - IDECanarias)

en 1862 se conocía su existencia (Onrubia Pintado et alii, 2008: 92-97). Dicho hallazgo recibe tal expectación que las pinturas comenzaron a deteriorarse de manera progresiva desde fechas tan tempranas (Batllori y Lorenzo, I900: I03-IIо; Stone, I887: 54). La autenticidad de estos emplazamientos generó bastantes dudas, razón por la que hubo un parón en la investigación sobre las pinturas y los grabados de la isla.

Años después, finalizada la Guerra Civil Española, se crean las comisarías arqueológicas durante el franquismo, momento en el que se formularon los cargos de comisarios provinciales de excavaciones arqueológicas. En el caso de la Provincia de Las Palmas cayó sobre la figura de Sebastián Jiménez Sánchez. Aunque por otro lado, hubo también un comisario local como fue el párroco de Telde, Pedro Hernández Benítez (Ramírez Sánchez, 2000: 424). Estos contribuyeron en las décadas de los años 40 y 60 al estudio de emplazamientos con grabados como el Barranco de Balos (Hernández Benítez, I945: 7-ro; Jiménez Sánchez, 1962) y otros emplazamientos con pinturas como Majada Alta (Jiménez Sánchez, I965), la Cueva del Péndulo (Jiménez Sánchez, I970) o la Cueva del Moro (Jiménez Sánchez, I963).

A partir de los años 70 comienzan a realizarse en Canarias estudios de arte rupestre desde un punto de vista más científico, por lo que debemos destacar los trabajos que se llevaron a cabo, sobre todo, en los emplazamientos más emblemáticos como el Macizo de Balos (Beltrán Martínez, 1971) y la Cueva Pintada de Gáldar (Beltrán Martínez y Alzola González, 1974). 
No obstante, existen también otras investigaciones como la tesis doctoral de Mauro Hernández, defendida en 1973, que incluye el estudio de los grabados de todo el Archipiélago Canario, aunque se centra más en la isla de La Palma. En Gran Canaria su investigación aborda prácticamente los mismos yacimientos que trabajó Beltrán, aunque discrepa con este en cuanto a la cronología e iconografía de los grabados (Hernández Pérez, 1973; 1996a; 1996b). Por aquella época existía también la CAMC (Comisión de Arqueología del Museo Canario), un grupo de aficionados a la arqueología que dio a conocer numerosos emplazamientos de arte rupestre, sobre todo, con grabados (CAMC, 1974).

Finalmente, durante los últimos años, quien más ha abordado la temática de trabajos relacionados con el arte rupestre en Gran Canaria ha sido el arqueólogo Julio Cuenca, quien ha dado a conocer varias estaciones de petroglifos (Cuenca Sanabria, 1992; 1995; 1997; Cuenca Sanabria et alii, 2004), pero centrando buena parte de su obra en las cuevas con representaciones de triángulos púbicos (Cuenca Sanabria et alii, 2004; Cuenca Sanabria, 2008). Quienes también han trabajado los yacimientos con arte rupestre han sido algunos investigadores de la Universidad de Las Palmas de Gran Canaria, encabezados por Ernesto Martín, que han dado a conocer algunas estaciones (Martín Rodríguez et alii, 1992; Martín Rodríguez, 2002) y aplicaron nuevas técnicas de documentación y registro en el Barranco de Balos (Martín Rodríguez et alii, 2007; 2008). Cabe destacar también una tesis doctoral que ha abordado el estudio de las cuevas pintadas de Gran Canaria, un trabajo que ha tenido en cuenta no solo los espacios con motivos representados, sino también la pintura mural de cuevas y abrigos (Hernández Rodríguez, 1997).

No obstante, a pesar de la tradición existente en trabajos de arte rupestre en Gran Canaria, no se han tenido en cuenta aspectos de especial interés como son las superposiciones de motivos, el análisis estilístico, la cronología relativa de los grabados, su análisis territorial o la aplicación de análisis de imagen para captar en las rocas lo que no se puede visualizar con el ojo desnudo. Por esta razón, creemos que es importante comenzar a analizar con más detalle los emplazamientos de este tipo como pretendemos en el presente trabajo.

\section{Objetivos}

$\mathrm{El}$ arte rupestre y, sobre todo, el pictórico es un patrimonio frágil, no solo por la afección que se pueda generar sobre los pigmentos por los agentes naturales, sino también por los antrópicos. En la isla de Gran Canaria cada vez es más frecuente la visita a los enclaves arqueológicos por personas que sienten curiosidad por la arqueología, o simplemente por aficionados que juegan a ser profesionales de esta disciplina. El acceso descontrolado a los yacimientos de este tipo pone en peligro la conservación de los mismos, pero no es algo nuevo. Investigadores que nos precedieron utilizaron también técnicas de documentación bastante destructivas (Sosa-Alonso, 2018: 308-309). Por esta razón, el objetivo principal de este trabajo es la documentación y el registro de las pinturas con figuras humanas. Una labor que urge de manera considerable, ya que durante los últimos años estos espacios arqueológicos no han sido objeto de estudios que puedan asegurar el conocimiento de unos grafismos que podrían desaparecer o alterarse más de lo que están en un futuro próximo.

Considerada la importancia de documentar y registrar los paneles con figuras humanas utilizando las técnicas actuales, queremos aprovechar para extraer más información que nos ayude a entender los procesos de ejecución de las mismas. Para ello nos basaremos en el primer calco digital que hemos realizado de estos yacimientos, apoyándonos en el análisis de las imágenes realizadas en campo con la ayuda de herramientas como DStretch ${ }^{\circledR}$ y Photoshop $^{\circledR}$. El análisis de imagen nos ayuda a ver lo que no podemos con el ojo desnudo, además de proporcionarnos una silueta de los motivos más realista y objetiva que las que se han conseguido con anterioridad.

Finalmente, al tratarse de un trabajo arqueológico, precisamos de interpretación. Somos conscientes de lo difícil y aventurado que puede llegar a ser interpretar unos grafismos ejecutados por poblaciones que ya no existen. Es por ello que basaremos nuestras explicaciones a través de los datos obtenidos, teniendo en cuenta la morfología de las pinturas y el contexto microespacial y macroespacial en el que se localizan. 
Con este estudio lo que se pretende demostrar es que los motivos antropomorfos pintados en cuevas y abrigos de Gran Canaria albergan más información de la que se ha pensado hasta el momento. Prueba de ello es la existencia de trazos y/o motivos superpuestos y las diferencias de estilos y técnicas que en un futuro próximo podrían aportarnos datos clave para entender las cronologías relativas de dichos emplazamientos. Es por ello que nuestra elección del motivo antropomorfo para este estudio se justifica teniendo en cuenta que se trata de un motivo recurrente y reconocible. Por tanto, como hipótesis de parti$\mathrm{da}$, apreciamos que los antropomorfos pintados no se parecen entre sí. Motivo suficiente para considerar que los indígenas canarios vivieron en la isla durante más de I 500 años y en diferentes zonas, por lo que creemos que dichas figuras humanas no fueron ejecutadas por personas que vivieron en un mismo momento ni tampoco compartieron las mismas inquietudes cognitivas. En resumidas cuentas, la información arqueológica que aporta el arte rupestre en la isla es mucho más compleja de lo que se ha pensado.

\section{Metodología}

Los métodos aplicados para conseguir los resultados que presentamos en adelante pueden dividirse en dos fases. La primera tiene que ver con las labores de campo, la documentación y el registro in situ utilizando técnicas no invasivas, es decir, sin tocar las pinturas bajo ningún concepto, a través de la fotografía y la fotogrametría digital. La segunda fase comprende el trabajo de gabinete en el que hemos desarrollado los modelos tridimensionales, el análisis de imagen y finalmente, los calcos digitales.

Durante el trabajo de campo, una vez identificados cada uno de los motivos pintados, hemos procedido a la realización de fotografías de cada uno de los paneles. Concluido este paso, hemos procedido a la realización de las fotogrametrías panel por panel. Para ello hemos utilizado una cámara réflex Canon IrooD apoyada sobre un trípode para estabilizar la captura de las imágenes. La fotogrametría es indispensable, pues nos permite generar modelos tridimensionales mediante series de fotografias alrededor de los paneles o emplazamientos arqueológicos, teniendo en cuenta que dichas fotos han de realizarse con distinta perspectiva y óptica (Pereira Uzal, 2013; Marchante Ortega, 2015: 167). Cuando finalizamos este proceso, el procedimiento a seguir consiste en la elaboración del diario de campo en el que tomamos nota de la descripción de las pinturas y del contexto en el que se localizan, a qué se asocian, etc.

El trabajo de gabinete es la parte más complicada de los procesos metodológicos. Pues es delante del ordenador donde nos damos cuenta de la calidad de los datos recopilados en campo.

Para realizar los modelos tridimensionales necesitamos las imágenes tomadas a través de la fotogrametría. Esto nos permite conocer el volumen y las dimensiones de los soportes sobre los que se encuentran los paneles, detalles que no se aprecian en una simple fotografía. El software que hemos utilizado para realizar los modelos tridimensionales es Agisoft Photoscan ${ }^{\circledR}$ (figura 2).

En segundo lugar, una vez recopiladas las imágenes en 2 y 3 dimensiones hemos realizado el análisis de las mismas a través del plugin $\mathrm{DStretch}^{\circledR}$ del software Image $\mathrm{J}^{\circledR} \mathrm{y}$ de Photoshop ${ }^{\circledR}$. Esto nos ayuda a resaltar las pinturas que por cuestiones de conservación son difíciles de apreciar por el ojo humano. El plugin de DStretch ${ }^{\circledR}$ ha sido creado por John Harman para el procesado específico de fotografías con arte rupestre pictórico (Harman, 2008 [2005]). Aunque en el caso que nos ocupa también lo hemos utilizado sobre los grabados de Gran Canaria con resultados positivos (Sosa-Alonso, 2019; 202I). Realizado el análisis de imágenes con DStretch ${ }^{\circledR}$, dichas fotografías vuelven a ser analizadas con las herramientas de Photoshop ${ }^{\circledR}$ para obtener el mayor contraste posible y crear los calcos con la ayuda de las imágenes obtenidas.

En último término, el resultado es la realización del calco digital. Una vez hemos obtenido las imágenes analizadas podemos extraer de las fotografías los espacios en los que se localizan los restos de pigmentos. Lo cual nos ayuda a ver lo conservado, a entender lo pintado, cómo se pintó y apreciar las pinturas que fueron realizadas. Los calcos de las pinturas antropomorfas de Gran Canaria serán mostrados en los siguientes epígrafes. 


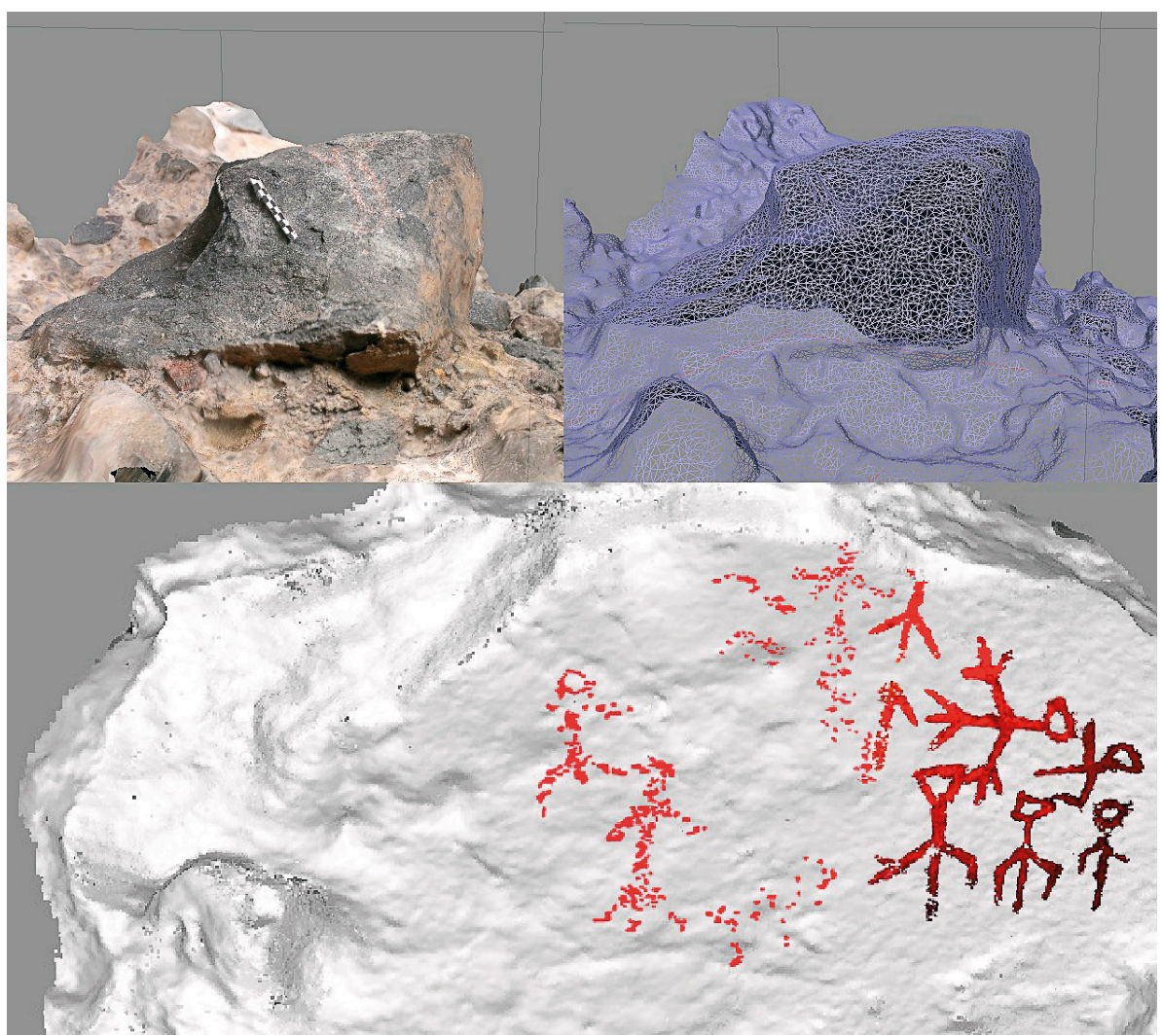

Figura 2. En la parte de arriba tenemos el modelo tridimensional del panel 2 de Majada Alta (a la izquierda la malla con textura y a la derecha modelo de teselas) y en la parte baja el calco de las pinturas del panel 1 sobre las clases de puntos de un modelo $3 \mathrm{~d}$

Figure 2. In the upper part we have the three-dimensional model of panel 2 of Majada Alta (on the left the textured mesh and on the right the tesserae model) and in the lower part the tracing of the paintings in panel 1 on the classes of points from a $3 d$ model

\section{El abrigo de Majada Alta}

Se trata de un espacio arqueológico condicionado por su aislamiento respecto a los asentamientos indígenas de la zona. Se localiza en un abrigo al margen izquierdo de un pequeño barranco conocido como Cañada del Cerrojo o Cañada Grande, que viene a desembocar en la presa de la Majada Alta, comúnmente conocida como Presa de Las Niñas. Este abrigo está compuesto por una pequeña cavidad natural de I,5 $\mathrm{m}$ de fondo por 3,4 $\mathrm{m}$ de largo, cuya planta es de tendencia semicircular con paredes irregulares (figuras 4 y 5 ).

Las pinturas antropomorfas de Majada Alta fueron descubiertas en el año I960 por Jesús Cantero Sarmiento y Félix González de la Huerta. Al poco tiempo fueron estudiadas por Sebastián Jiménez, quien publica un artículo monográfico de los motivos antropomorfos (Jiménez Sánchez, I96r: 5-10).
Durante los procesos del trabajo de esta época se cometió el error de rellenar con tiza blanca el contorno de algunos motivos para que pudiesen ser vistos en las fotografías, una acción que dañó considerablemente los pigmentos (Hernández Rodríguez, I997: 253). En el año 1974 la Comisión de Arqueología del Museo Canario insertó este abrigo en un inventario (CAMC, 1974: 215) y tres años después realizaron un calco (Hernández Rodríguez 1997: 226). Posteriormente, Rubén Naranjo publica un artículo sobre estas pinturas mencionando, al igual que Sebastián Jiménez, que estas figuras se realizaron con almagre disuelto en grasa animal y que por el ancho que tienen fueron aplicadas con los dedos sobre la roca (Naranjo, 1983: 15-17). Celso Martín de Guzmán interpreta también estas pinturas dividiéndolas en cuatro grupos diferentes. En el panel de mayores dimensiones distingue a cinco individuos en movimiento, tres individuos en posición frontal, 


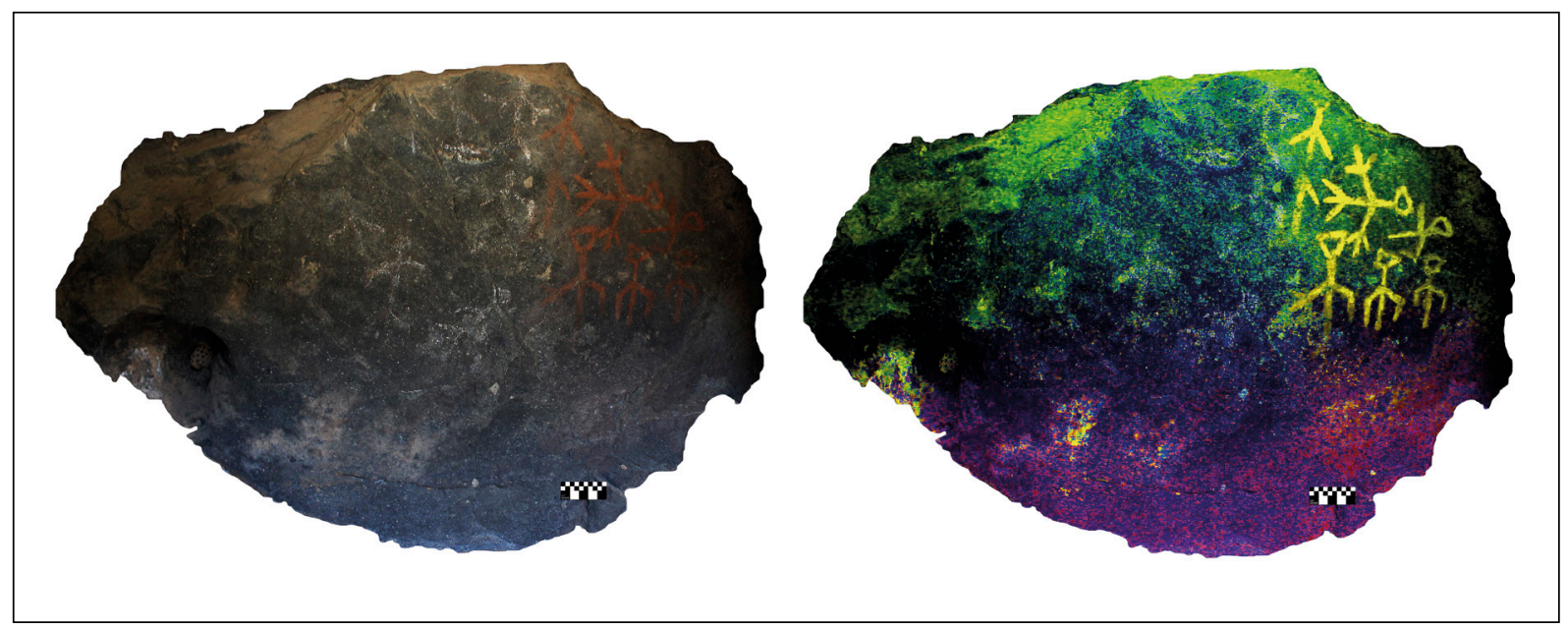

Figura 3. A la izquierda tenemos la ortofoto con el estado y coloración original del panel 1 de Majada Alta y a la derecha la misma imagen tratada con DStretch ${ }^{\circledR}$

Figure 3. On the left we have the orthophoto with the original state and coloration of panel 1 of Majada Alta and on the right the same image treated with DStretch ${ }^{\circledR}$

estando uno de ellos con los brazos abiertos. Y, por otro lado, menciona un individuo aislado en una roca más pequeña (Martín de Guzmán, 1984: 776-777; Hernández Rodríguez, 1997: 227).

La realidad es que la mejor descripción del yacimiento y de las pinturas en concreto está reflejada en una tesis doctoral sobre la pintura rupestre de Gran Canaria, realizada por Narciso Hernández y publicada en 1997. En este trabajo hay mayor detalle de las dimensiones del abrigo y de las figuras. Hernández describe que las pinturas se realizaron siguiendo un trazado lineal cuyo grosor oscila entre los I,2 y $2 \mathrm{~cm}$. En su calco observa I3 figuras antropomorfas y que en la otra piedra (panel 2) aparecen dos figuras antropomorfas sin brazos (Hernández Rodríguez, 1997: 255). En nuestra intervención sobre los paneles, los calcos que hemos realizado han sido digitales sin tocar los pigmentos bajo ningún concepto. Y ha sido gracias al análisis de imagen realizado con DStretch ${ }^{\circledR}$ que hemos captado las zonas en las que se localizan y conservan los pigmentos, sin lugar a confusión por la capa de tiza que repasa los motivos peor conservados.

Nuestro calco no ha consistido en contornear las figuras, sino en extraer de las imágenes tratadas los espacios con pigmentos. Haciendo del calco una representación más fidedigna y menos subjetiva del pigmento rojo que se encuentra sobre la roca y que describimos de la siguiente manera:
El panel I se trata de una roca circular que alberga hasta I4 motivos rupestres, de los cuales 6 están bien conservados mientras que el resto casi no se aprecian con claridad sin ayuda de análisis de imagen. El calco que mostramos en la figura 3 se trata de la extracción del pigmento con la coloración tal y como se conserva en la actualidad. Claramente los motivos de la derecha son los mejor conservados, lo que tiene que ver con el agarre de la pintura sobre la corteza de esa parte de la roca cuya porosidad agarra mejor el pigmento. La parte de la izquierda, donde se encuentran los motivos rallados con tiza se conserva mucho peor.

La disposición de los grafismos es interesante, pues los motivos II, I2 y I3 siguen una misma morfología y estilo parecido. Ambos tienen ausentes las piernas, los brazos arqueados y la cabeza hueca por dentro. El motivo ir, pensamos que es el primero en haberse realizado por su tamaño mayor a los otros dos y por estar más completo. A diferencia de los otros posee «dedos» en la mano izquierda y la cabeza triangular. Mientras tanto, los otros dos motivos ( 12 y I3) van reduciendo su tamaño y son realizados con menos detalle, pues todo apunta a que el pintor o pintora intentó ajustarse a las dimensiones del panel para no salirse encajando dichas figuras. Esto también es visible en los motivos 6 y 7 , que se ajustan a la parte alta de la roca, teniendo el motivo 5 más espacio longitudinal, mientras que los otros dos motivos (6 y 7) aparecen en horizontal para poder 


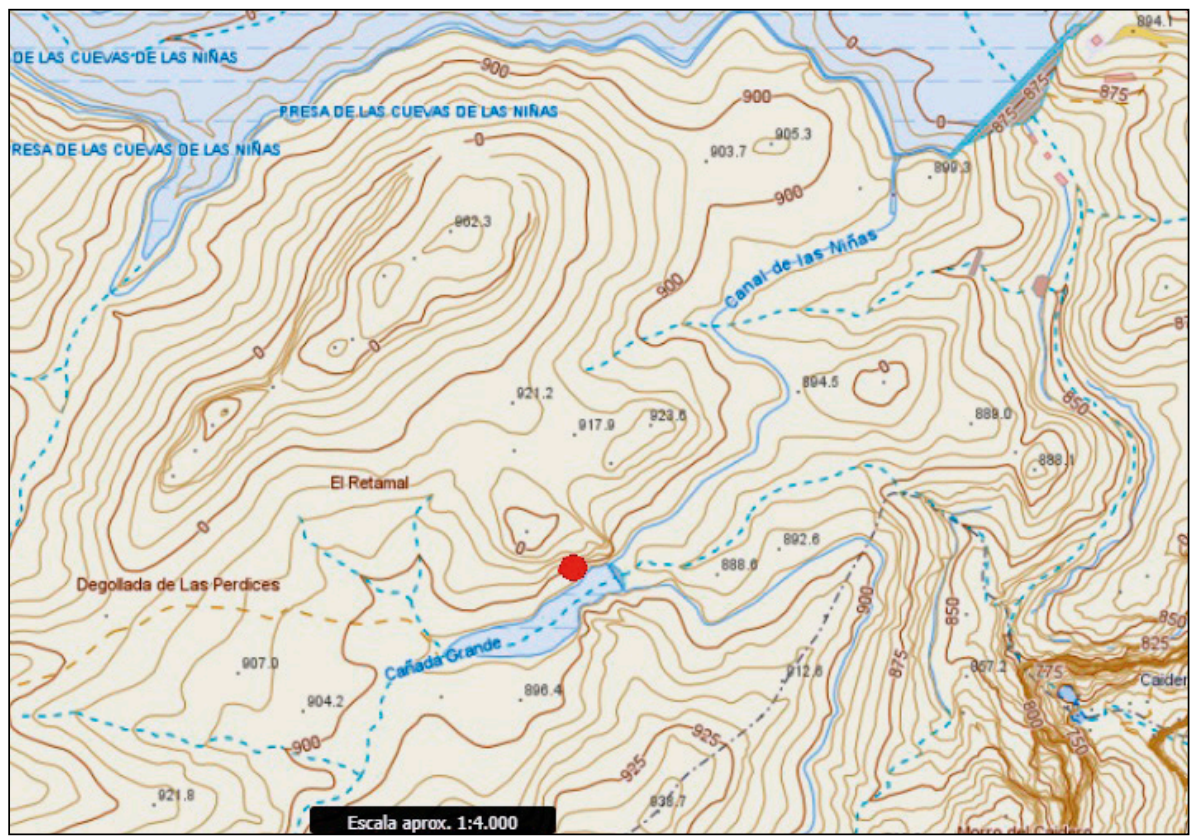

Figura 4. Localización del abrigo pintado de Majada Alta (Sistema de Información Territorial de Canarias - IDECanarias)

Figure 4. Location of the painted shelter of Majada Alta (Canary Islands Territorial Information System - IDECanarias)

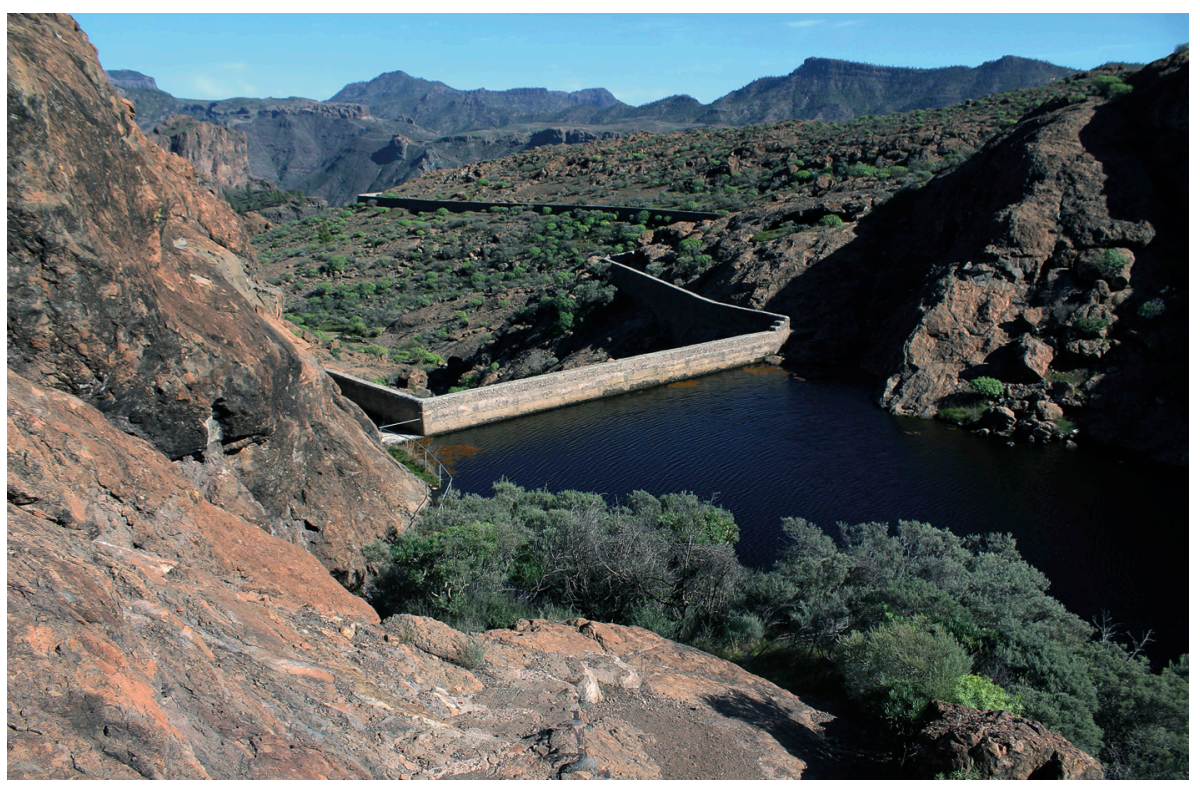

Figura 5. Vista exterior del abrigo de Majada Alta

Figure 5. Exterior view of the Majada Alta shelter

ser representados. El autor tuvo espacio suficiente para realizar detalles al motivo 6 , representando las manos y una línea entre las dos piernas, lo cual no sabemos si representa el pene del individuo o simplemente se trata de la continuidad del trazo del torso. En el motivo 7, en cambio, vemos un espacio menor y limitado para realizar ciertos detalles. Lo cual es visible no solo en su reducido tamaño sino en la imposibilidad de representar el brazo izquierdo arqueado como el derecho al toparse con la cabeza de la figura anterior.

Como podemos observar, el resto de motivos son mucho más difíciles de percibir por su estado de conservación. El motivo I no sabemos si quiera si se trata 


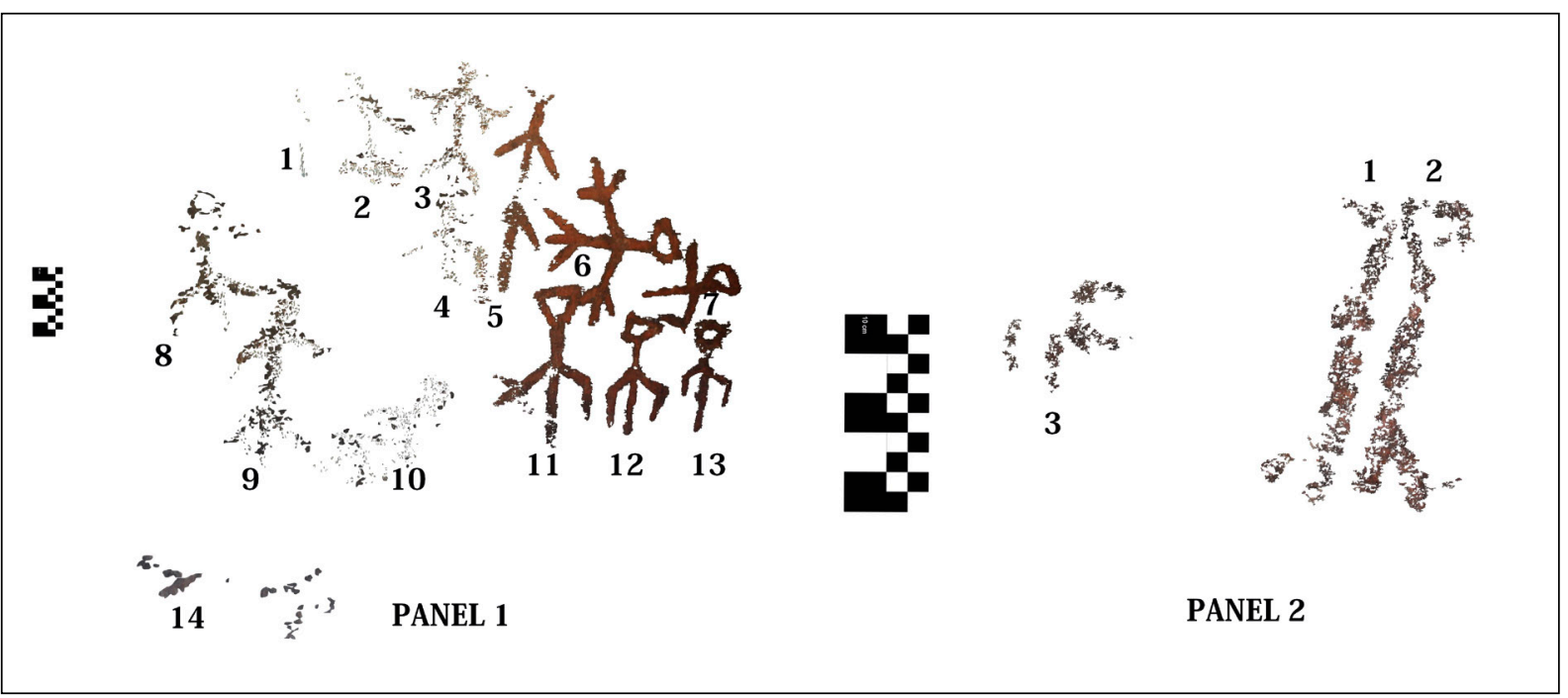

Figura 6. Calco digital de los pigmentos de los paneles 1 y 2 del abrigo de Majada Alta (Tejeda)

Figure 6. Digital tracing of the pigments of panels 1 and 2 of the Majada Alta shelter (Tejeda)

o no de un antropomorfo. Lo que si vemos destacable es que las cabezas de dichas representaciones están más redondeadas, cuya disposición en el panel es distinta, es decir, con mayor espacio entre los motivos. Esto nos hace pensar en la posibilidad de que las pinturas de la izquierda y de la derecha fueron realizadas en distinto momento. Planteamos como hipótesis que, al estar los motivos de la derecha más apretados, da la apariencia de que los primeros pintores aprovecharon todo el panel rocoso siguiendo un estilo determinado. Dichos motivos no se conservan en la actualidad y probablemente, o fueron repasados con otra estilización en una segunda fase (realizando los motivos peor conservados del lado izquierdo), o simplemente, en un momento posterior otro pintor realizó los motivos a su manera y modo de ver. Lo que está claro que las representaciones humanas no se parecen. Por lo que creemos que son varios autores en distintos momentos los que aplican almagre rojo sobre esta roca.

Algo parecido pasa con el panel 2, cuyos motivos, supuestamente antropomorfos (I y 2), nada tienen que ver con los del panel I. Cuesta ver una representación humana en dichas siluetas, pues no conservan los brazos. Sin embargo, el contexto nos hace pensar en que sí se trata de motivos antropomorfos pero estilizados y esquematizados. Cabe decir que, durante el proceso de calco sobre las imágenes analizadas hemos descubierto un nuevo motivo, no visto por los investigadores precedentes, a la izquierda de este panel. En él vemos hasta cuatro trazos de pintura, aplicada posiblemente con el dedo, pero por cuestiones de conservación del motivo nos es imposible, de momento, adscribir una tipología. Pues no sabemos si se trata de otra representación humana o un motivo geométrico (figura 6).

\section{El abrigo de Cuevas de Cubas}

Las pinturas de Cuevas de Cubas se localizan en un espacio arqueológico que ya era conocido con anterioridad (figuras 7 y 8). Se trata de un poblado troglodita excavado en la roca por los indígenas cuya reutilización y uso llega hasta nuestros días. El yacimiento arqueológico estaba recogido en la carta arqueológica municipal de Telde desde el año I989 como un yacimiento en el que se encontraban cuevas naturales y artificiales con material arqueológico en superficie y con la presencia en la parte alta del poblado de un panel con grabados rupestres, cuyo calco fue publicado por el arqueólogo Julio Cuenca (1996, I86).

En el año 20I7, durante una campaña de documentación de los grabados existentes hallamos un abrigo con seis paneles de pinturas rupestres. Entre ellas se encontraban figuras humanas, geométricas y otras indeterminadas por su débil estado de 


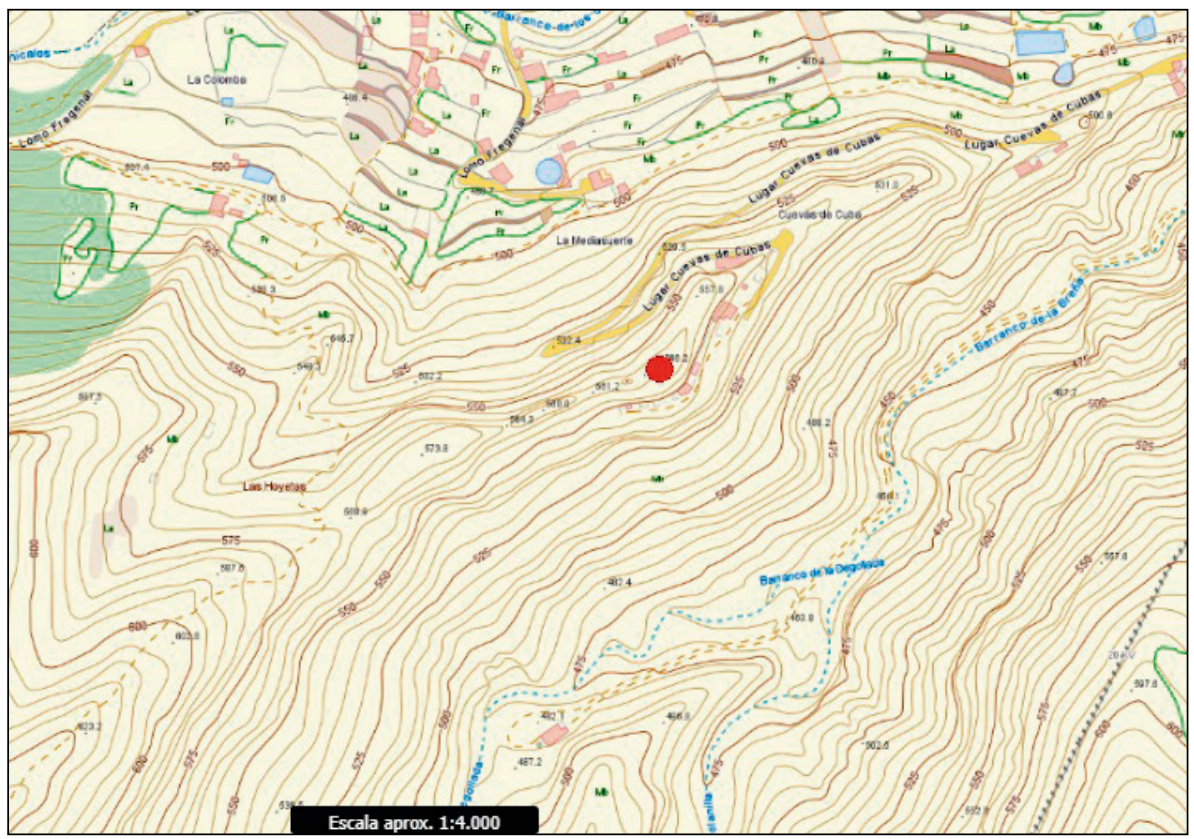

Figura 7. Localización del abrigo pintado de Cuevas de Cubas (Sistema de Información Territorial de Canarias - IDECanarias)

Figure 7. Location of the painted shelter of Cuevas de Cubas (Canary Islands Territorial Information System - IDECanarias)

conservación. Estas pinturas, al igual que el panel con grabados, se localizan en la parte alta del poblado. Los petroglifos se encuentran en una roca destacada del territorio, las pinturas, en cambio, a pesar de estar dentro del abrigo, se encuentran en otra de las rocas destacadas, por lo que a nuestro modo de ver, tal y como mencionamos en la publicación que realizamos en su momento (Sosa-Alonso et alii, 2020), no solo son importantes las pinturas y grabados en sí, sino los elementos naturales destacados en el territorio en los que se localizan.

De los seis paneles con pinturas que hallamos en el abrigo, solo dos de ellos poseen figuras antropomorfas. El primer panel, se dispone en el lado izquierdo de la cavidad, es el que mayor volumen de pigmento posee y el que más destaca. Podemos observar en él con total certeza una figura antropomorfa, en la que no se notan trazos de la cabeza pero sí posee las piernas abiertas y algunos dedos de la mano derecha marcados. Debido a que en la parte izquierda tenemos una dispersión de pigmento por todo el panel no sabemos de momento si en la mano izquierda la figura posee también dichos dedos. Sin embargo, podemos percibir que en este panel existe una superposición. Es decir, que debajo de la dispersión del pigmento rojo existen motivos pintados, también de rojo, que son difíciles de delimitar por el momento. Por tanto las figuras son indeterminadas, pero no descartamos la existencia de motivos antropomorfos. Sobe todo, porque podemos percibir algunos trazos.

En el segundo panel, el cual se conserva muy poco y solo lo podemos apreciar a través de análisis de imagen con DStretch ${ }^{\circledR}$, en nuestro primer estudio observamos una sola figura humana, también con las piernas abiertas y los brazos arqueados. Sin embargo, en un segundo análisis de las imágenes hemos podido captar a la derecha de este motivo otro posible antropomorfo. Debido al tipo de soporte, $\mathrm{cu}^{-}$ ya base es más porosa que el basalto del panel $\mathrm{I}$, los pigmentos no han agarrado bien y están más desgastados. Además, este panel, también en el lado izquierdo del abrigo está más cerca de la entrada, por lo que los agentes naturales y/o antrópicos han podido dañar más su conservación. Uno de los aspectos a destacar en este segundo estudio del panel es la existencia de un trazo de pigmento entre las piernas del motivo de la izquierda. Lo cual, al igual que para los motivos de Majada Alta, no sabemos si se debe a la continuidad del torso o a un intento de representar el falo de una figura masculina (figura 9). 


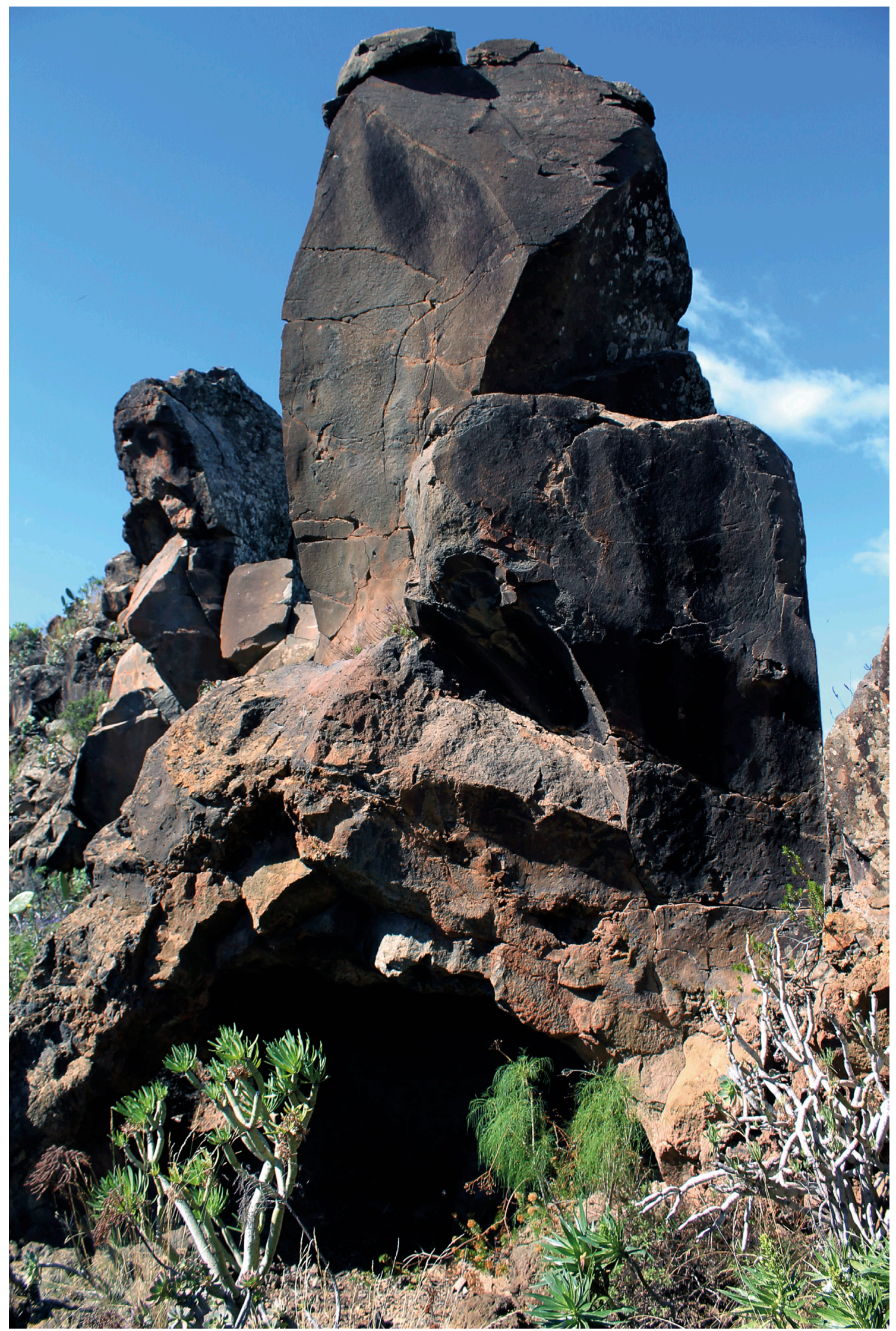

Figura 8. Abrigo de Cuevas de Cubas cuyas pinturas se encuentran en su interior

Figure 8. Shelter of Cuevas de Cubas whose paintings are inside 


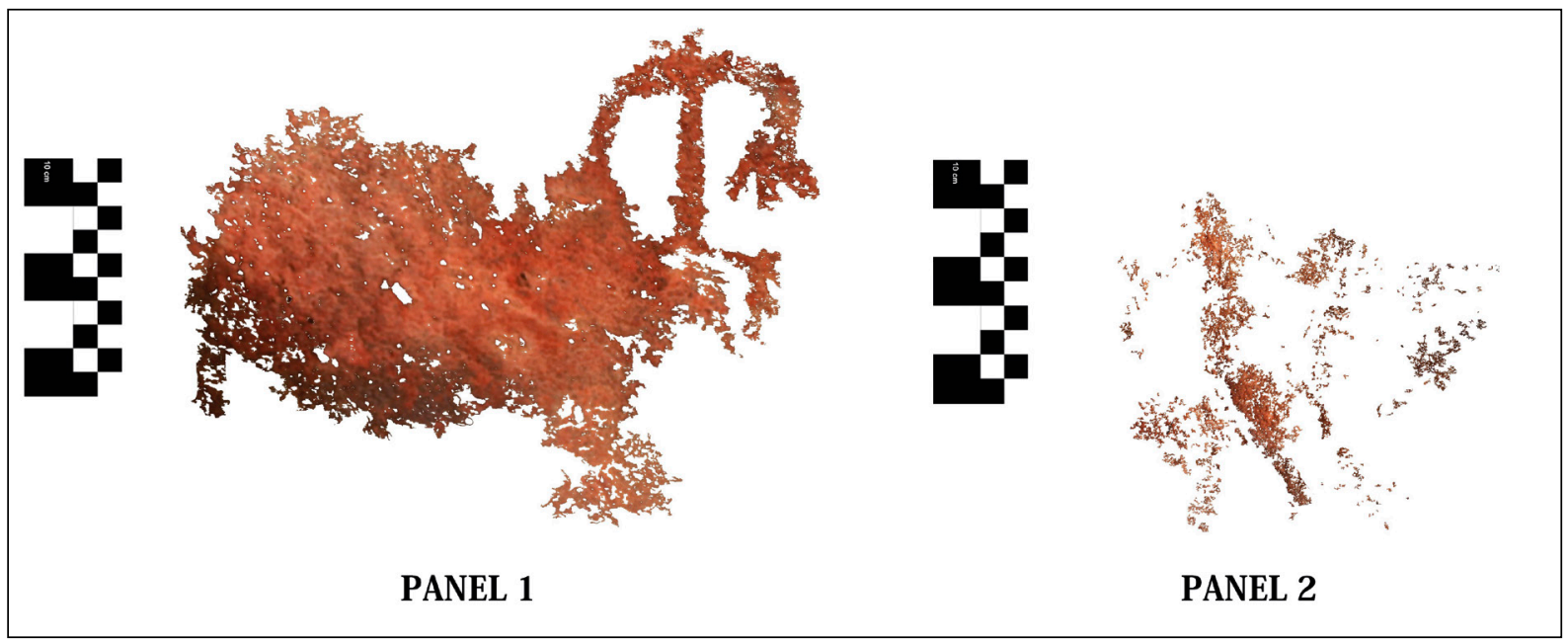

Figura 9. Calco digital de los pigmentos de los paneles 1 y 2 del abrigo de Cuevas de Cubas (Telde)

Figure 9. Digital tracing of the pigments from panels 1 and 2 of the Cuevas de Cubas shelter (Telde)

\section{La Cueva del Moro}

En el término municipal de Agaete, en una zona denominada como Las Moriscas, se localiza la Cueva del Moro (figura Io). A simple vista, posee todas las características de un yacimiento de factura indígena. Se compone por una cueva y por los restos de una estructura delante de la entrada de la misma, un espacio que alberga numerosos restos en superficie como industria lítica, cerámica y, sobre todo, restos malacológicos. La cavidad que alberga las pinturas se compone de dos estancias artificiales excavadas en la roca. En la primera de ellas, sabemos con certeza que al menos su primer uso fue el de granero colectivo. Testigo de ello son los numerosos silos excavados en la roca, algo muy propio de las poblaciones indígenas de Gran Canaria. Y por otro lado, tenemos una segunda estancia, cuya funcionalidad desconocemos por la falta de intervenciones arqueológicas en dicho espacio (figura II).

La cueva del Moro se da a conocer por vez primera a finales del siglo xIx en un informe científico de René Verneau (I887: I89), pero no es hasta los años 60 del siglo pasado que se mostraron sus pinturas por parte de Sebastián Jiménez (1963), donde se muestra un croquis de dos de las tres pinturas localizadas en la cavidad. Estas pinturas fueron mencionadas con posterioridad en otros trabajos en los que algunos investigadores dudaron de su autenticidad (Martín de Guzmán, I978; Beltrán
Martínez, I985: 19; Onrubia Pintado, 1986: 252). En los años 8o, se da a conocer un tercer motivo pintado (Naranjo Rodríguez, 1983: 15-I7), que se encuentra en la primera estancia artificial de la cueva y que es más difícil de visualizar. A pesar de ello, otros trabajos posteriores como la tesis de Narciso Hernández siguen considerando estas figuras como antropomorfas (Hernández Rodríguez, 1997: 59).

Comenzamos a documentar los motivos que primero se dieron a conocer, los que se encuentran en la segunda estancia catalogados como figuras antropomorfas, cuya pared hemos denominado como panel I. La figura de la izquierda posee una morfología cruciforme, mientras que la de la derecha consideramos indeterminada, a pesar de que se ha considerado desde un primer momento como una figura femenina (Jiménez Sánchez, 1963; Hernández Rodríguez, I997: 60). El segundo panel, dado a conocer en los 80 por Rubén Naranjo (I983: I5-I7), se localiza en la primera estancia artificial, en la parte superior derecha de la portada de acceso a la segunda estancia. Gracias al análisis de imagen de DStretch ${ }^{\circledR}$ hemos observado que también se trata de una figura cruciforme y no claramente antropomorfa con las piernas marcadas como se ha insinuado en otros calcos (Hernández Rodríguez, I997: 63).

Ambos paneles han sido realizados con almagre rojo, al igual que el resto de pigmentos ocres del resto de cuevas indígenas de la isla. La diferencia radica en el soporte. Son las únicas pinturas supuestamente 


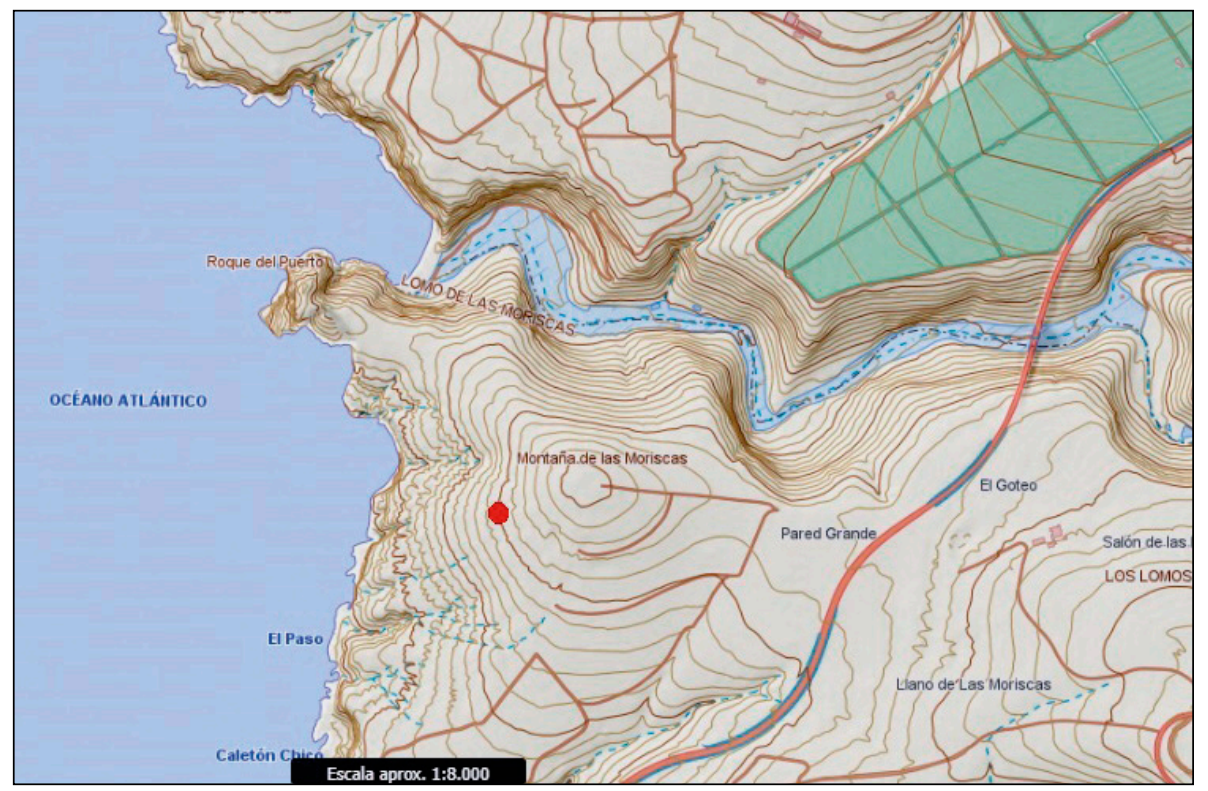

Figura 10. Localización la Cueva del Moro (Sistema de Información Territorial de Canarias IDECanarias)

Figure 10. Location of the Cueva del Moro (Canary Islands Territorial Information System IDECanarias)

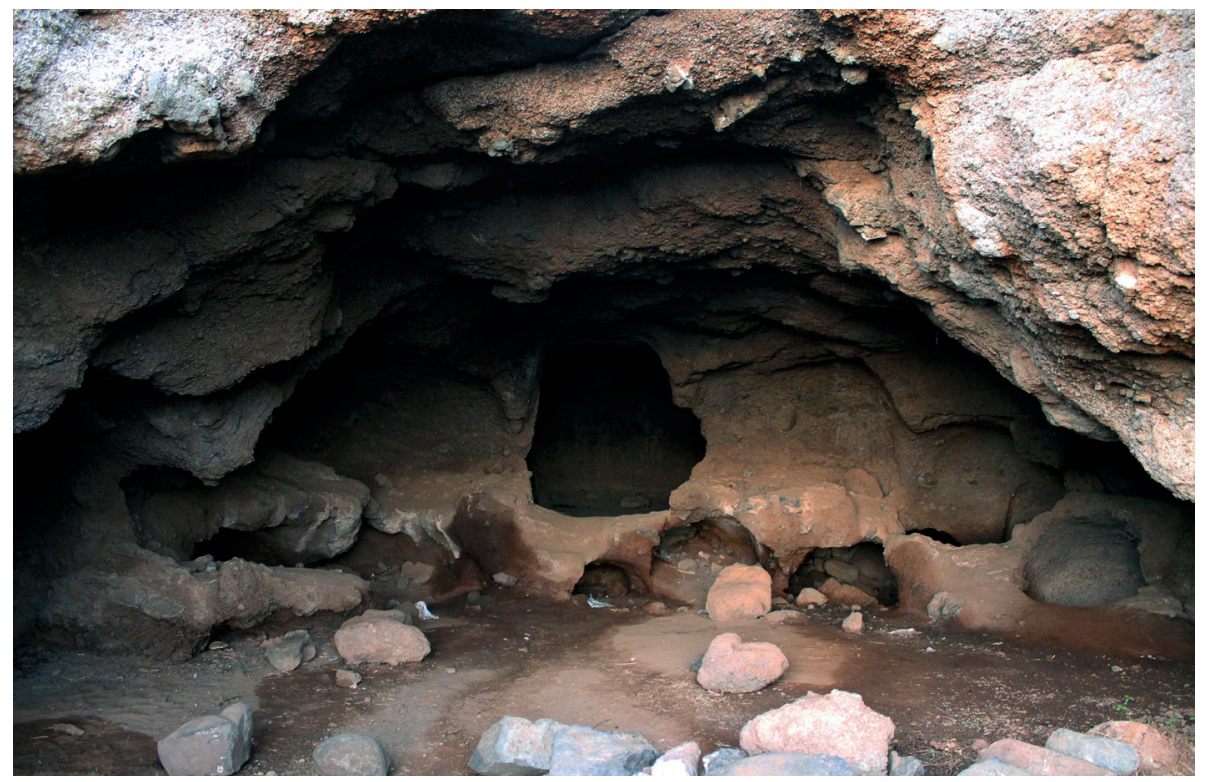

Figura 11. Estancia principal de la Cueva del Moro. En esta imagen se puede observar la entrada de acceso a la segunda estancia en el centro y los huecos en ambos lados donde se encontraban los silos para el almacenamiento de alimentos

Figure 11. Main room of the Cueva del Moro. In this image you can see the entrance to the second room in the center and the gaps on both sides where the silos for storing food were located

antropomorfas realizadas sobre toba volcánica. Esto es un dato interesante, pues las cavidades artificiales de este tipo suelen presentar un desgaste considerado a lo largo del tiempo, visible, en este caso, en la degradación de los silos en donde vemos que los granos de lapilli volcánico se han ido despedazando al igual que las argamasas que cubrieron las paredes en el pasado. Por esta y otras razones, que explicaremos con detalle en adelante, no es que dudemos de la autenticidad de las pinturas, sino que pensamos que pertenecen a un período posterior a la fase de uso indígena o aborigen de la cavidad (figura I2). 


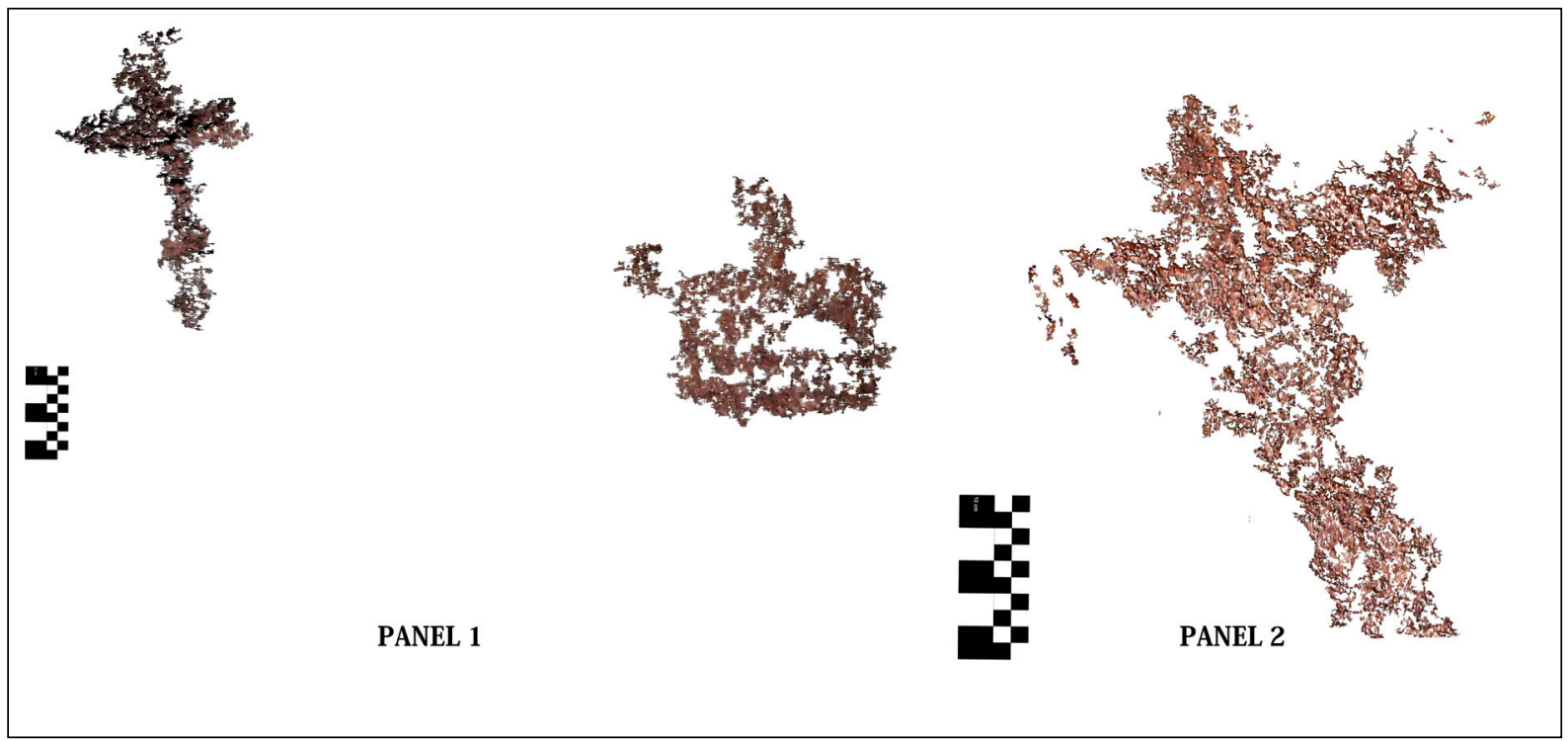

Figura 12. Calco digital de los pigmentos de los paneles 1 y 2 de la Cueva del Moro (Agaete)

Figure 12. Digital tracing of the pigments of panels 1 and 2 of the Cueva del Moro (Agaete)

\section{Discusión}

Las pinturas antropomorfas que presentamos en este trabajo, como hemos mencionado, pertenecen a tres espacios arqueológicos diferentes de la isla de Gran Canaria, distantes entre sí y en contextos diversos. A nivel morfológico, se puede asegurar a simple vista que no existe un estilo o escuela que nos asegure que dichas figuras han sido realizadas por el mismo grupo humano y mucho menos por la misma persona. Algo que sí podemos observar en algunos antropomorfos grabados en otros espacios rupestres. Si nos centramos en los detalles de las figuras podemos hacer una gran diferencia entre Majada Alta y Cuevas de Cubas con el yacimiento de Cueva del Moro. Las dos primeras estaciones de pinturas tienen varios aspectos en común. El primero es el soporte, cuyo pigmento ha sido realizado sobre rocas basálticas de textura sólida, es decir, en pequeños abrigos rocosos naturales mientras que la Cueva del Moro está en una cueva artificial de toba volcánica. El segundo es que las figuras de los abrigos tienen piernas representadas, dobladas o no al nivel de las rodillas, mientras que en la artificial no se aprecia este detalle. Y por último, en tercer lugar, en los abrigos pintados está presente, aunque no en todas las figuras, los dedos de las manos. Algo que si es perceptible en figuras antropomorfas de yacimientos con petroglifos de factura indígena como en el Barranco de Balos.
En cuanto a las técnicas de ejecución queda mucho por saber, pues precisamos de análisis físico-químicos de los pigmentos para conocer bien el tipo de aglutinante utilizado para la creación de los mismos. A simple vista, podemos percibir, según el grueso y morfología de los trazos pintados, que los antropomorfos realizados en abrigos naturales se pudieron hacer aplicando el pigmento con los dedos, mientras que en la Cueva del Moro no queda tan claro. Pensamos que en esta última se utilizó algún tipo de brocha ya que sería muy complejo que agarrase el pigmento del soporte, teniendo en cuenta la irregularidad y porosidad de la toba volcánica. No obstante, sería conveniente realizar en un futuro próximo pruebas experimentales para corroborar este planteamiento. Pero está claro que existe una diferencia técnica entre los yacimientos.

Sin embargo, a pesar de existir grandes diferencias entre los abrigos y la cueva artificial también existe disparidad entre Majada Alta y Cuevas de Cubas. La primera es la más evidente, tiene que ver con el número de figuras humanas representadas. En Cuevas de Cubas de momento hemos localizado tres antropomorfos (posiblemente existan más debajo del borrón de almagre del panel I), mientras que en Majada Alta tenemos hasta I7 figuras. En segundo lugar tenemos la asociación de motivos, en Cuevas de Cubas las figuras humanas están al lado de otras 
figuras geométricas, mientras que en Majada Alta solo vemos figuras humanas con un solo motivo, o parte de un motivo, que denominamos indeterminado por la falta de apreciación de la figura primigenia. Y en tercer lugar, mientras que en Majada Alta vemos algunas figuras en posición horizontal, esto no ocurre con las localizadas en Cuevas de Cubas.

Otro aspecto a tener en cuenta es el contexto. Cada espacio con pinturas antropomorfas pertenece a escenarios completamente diferentes. En Majada Alta se localizan en un abrigo pastoril. Un espacio que sigue estando vinculado con el ganado en la actualidad y cuyo topónimo «majada» nos habla de un lugar donde se recogen los pastores con el ganado por las noches. Al tratarse de un espacio perfecto para el resguardo de los trashumantes y al no vincularse con otro tipo de estructuras arqueológicas y/o material en superficie, creemos que este espacio en el pasado pudo tener también dicha vinculación. Por otro lado, el abrigo de Cuevas de Cubas, que sí tiene material lítico y cerámico de factura indígena en superficie, sedimentos en el suelo de la cavidad y se vincula a un espacio con grabados antropomorfos en una roca destacada en lo alto de un poblado troglodita, cuyo uso va desde la fase indígena hasta bien entrada la posterior a la conquista, nos ha hecho pensar, como ya hemos mencionado en la presentación de nuestro descubrimiento de 2017 (Sosa-Alonso et alii, 2020), que se trata de un espacio vinculado con el mundo mágico-religioso del poblado. Esto se debe a que se ubica en la cima del asentamiento, un patrón a seguir en muchos espacios arqueológicos indígenas de la isla relacionados con los famosos almogarenes donde se realizaban los ritos de estas poblaciones.

En cambio, el contexto de la Cueva del Moro dista mucho más de los dos espacios anteriores. Si bien es común la pintura roja o de otros colores en los graneros colectivos de Gran Canaria, ya sea en forma de zócalo o de pintura mural, este es el único granero que posee arte figurativo en su interior. Algo único y exclusivo que nos genera numerosas dudas.

A continuación mostramos en el siguiente gráfico (figura ${ }_{3}$ ) las diferentes unidades estratigráficas o unidades gráficas (en adelante UG) de los paneles con pinturas antropomorfas de la isla de Gran Canaria. Solo los paneles I y 2 de Majada Alta y el panel I de Cuevas de Cubas poseen diferencias en cuanto al tipo de pigmento y superposiciones. Las UG-r y 2 del panel I de Majada Alta representan los pigmentos en almagre rojo y la UG-3 la superposición del rallado con tiza. La UG-I del panel 2 de Majada Alta muestra el pigmento rojo, la UG-2 la superposición de tiza y la UG-3 un motivo indeterminado (también en pigmento rojo). En el panel I del abrigo de Cuevas de Cubas tenemos también tres unidades gráficas, todas ellas en almagre rojo. La UG-I representa la única figura antropomorfa clara, la UG-2 el borrón de pigmento que se encuentra a su izquierda y la UG-3 los trazos de figuras indeterminadas que posiblemente sean figuras antropomorfas que de momento no podemos apreciar en su totalidad.

Si nos resulta difícil establecer una relación entre las diferentes figuras antropomorfas pintadas en abrigos o cuevas, más complejo supone relacionar estas con los antropomorfos ejecutados mediante la técnica del grabado al aire libre. El yacimiento más representativo de grabados rupestres de Gran Canaria es el Barranco de Balos, en el que sí podemos apreciar la existencia de un estilo o escuela por la morfología de las figuras. El problema, es que en Balos no existe un solo estilo o escuela, pues en sus rocas se han grabado figuras humanas durante todas las épocas. Testigo de ello son las numerosas superposiciones de grabados, técnicas de ejecución, coloración de pátinas, contexto micro y macroespacial y disposición de figuras sobre los paneles. Ante esta complejidad nos surge la siguiente pregunta: ¿con qué antropomorfos de Balos podríamos relacionar las figuras pintadas? A decir verdad, poco se parecen, las técnicas de grabar y pintar son muy distintas. Lo que sí podemos observar, es que entre las figuras de Balos más antiguas se conserva un panel (figura I4) que posee una figura humana con los dedos marcados, algo también presente en Cuevas de Cubas y Majada Alta. La diferencia radica en que este panel de grabados no solo posee una figura humana, sino una geométrica y escritura líbico-bereber. Por esta razón nos es bastante complicado establecer una conexión segura entre las figuras grabadas y pintadas, ya que en las segundas no tenemos constancia por el momento de motivos 


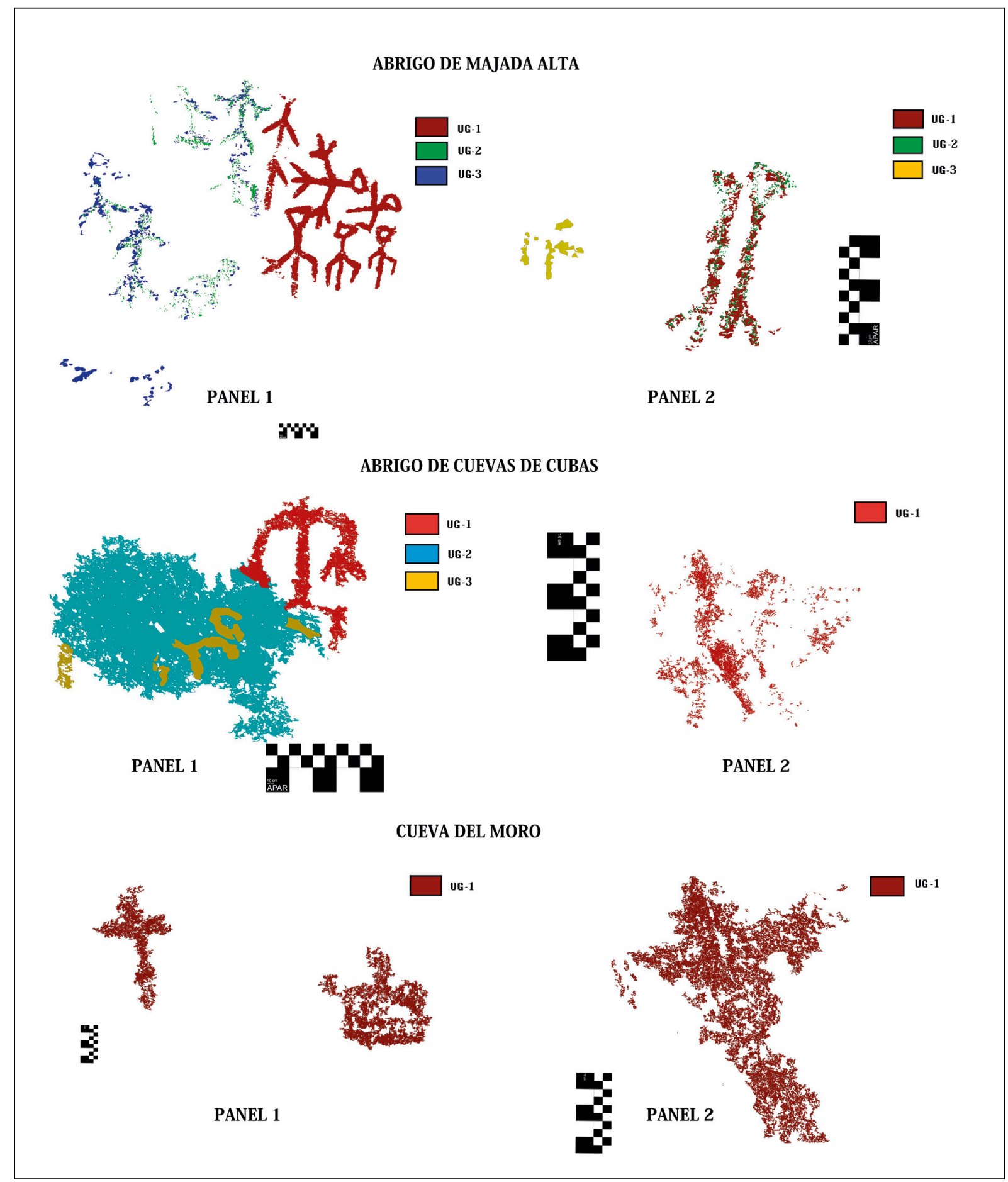

Figura 13. Unidades gráficas de las figuras antropomorfas pintadas de la isla de Gran Canaria

Figure 13. Graphic units of painted anthropomorphic figures on the island of Gran Canaria

alfabéticos pintados en ninguna de las estaciones rupestres de Gran Canaria. Debemos dejar claro también que, en Balos, existen otras figuras humanas que tienen los dedos de las manos y los pies marcados. Sin embargo, consideramos, bajo nuestras observaciones, ya que este yacimiento está en proceso de estudio, que esas figuras pertenecen a fechas relativamente recientes. Algo que podemos apreciar en una coloración de pátinas más clara, en la disposición secundaria en el panel de estos motivos, en las técnicas empleadas y, en ocasiones, por las superposiciones entre petroglifos. 


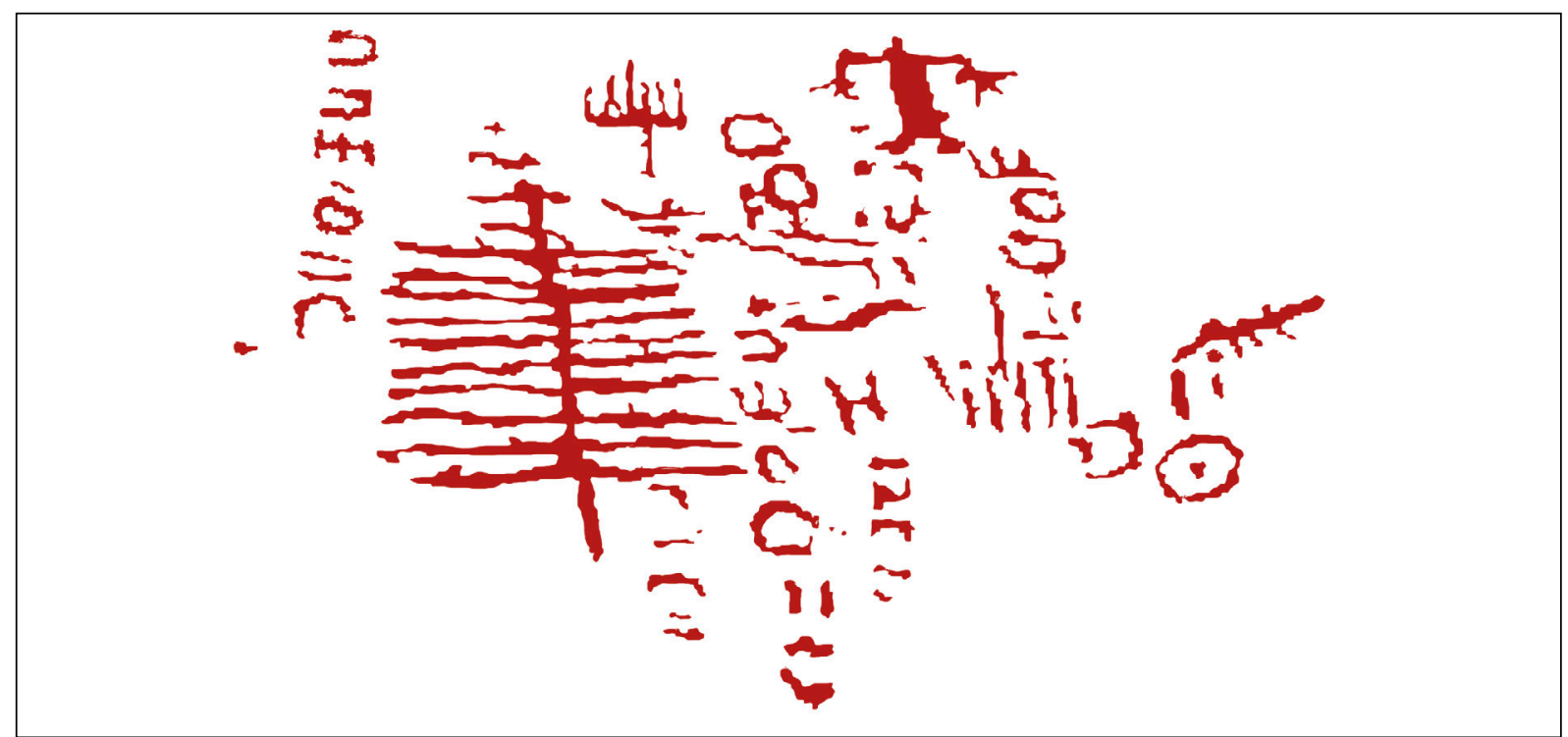

Figura 14. Calco de uno de los paneles del Barranco de Balos (Agüimes, isla de Gran Canaria)

Figure 14. Tracing of one of the panels of the Barranco de Balos (Agüimes, island of Gran Canaria)

\section{Conclusiones}

A simple vista parece fácil vincular las pinturas antropomorfas de Gran Canaria entre sí, independientemente del yacimiento en el que se localizan, este estudio ha servido para dejar claro las numerosas diferencias y las complejidades a las que nos enfrentamos a la hora de estudiar el arte rupestre, ya que no basta con que estén en espacios arqueológicos asociados a estas poblaciones. Si bien es verdad que la cultura indígena de Gran Canaria dista mucho de la sociedad colonial que se generó después, no significa que las inquietudes cognitivas de este pueblo que vivió durante más de un milenio en la isla tuviesen la necesidad de representar siempre lo mismo.

En Majada Alta las pinturas están aisladas de cualquier poblado, por lo que su frecuentación en el pasado no debió de serlo tanto como en Cuevas de Cubas, cuyo poblado se encontraba a escasos metros de las estaciones rupestres. Si Majada Alta es un abrigo pastoril, la cavidad de Cuevas de Cubas se trata de un espacio utilizado de manera frecuente en donde existen aún hoy sedimentos que nos puedan aportar datos a través de una excavación arqueológica en la misma. Todo apunta, como hemos dicho con anterioridad, a que este segundo espacio tenga vinculación con el mundo mágico-religioso de los antiguos canarios.
Sin embargo, la Cueva del Moro, cuyas pinturas se han visto cuestionadas en cuanto a su originalidad, no pensamos que se trate de una falsificación. El topónimo de «moro» Morro de las «moriscas» o Montaña «Morisca», que hace referencia de su vinculación y ocupación por los moriscos de esta zona en época colonial, nos obliga a reflexionar sobre la posibilidad de que dichas pinturas pertenezcan al último período de ocupación de la cueva en la etapa posterior a la conquista de los europeos. Donde sabemos sobradamente sobre la presencia de población morisca y negra en la zona de Agaete vinculada a los esclavos que trabajaban en los cultivos de caña de azúcar. Aparte de ello, en otros lugares de Gran Canaria cuyo topónimo se relaciona con moriscos como el Barranco de La Morisca (Telde) o llano de Las Moriscas (Ingenio) sabemos de la presencia de grabados rupestres en forma de cruz, un fiel reflejo de la morfología de estos supuestos «antropomorfos» pintados en Agaete. En la isla de Lanzarote existe también la peña rocosa de Omarén o Humarén, vinculada con población morisca y con la presencia de otro grabado cruciforme. En el último Coloquio de Historia Canario-Americana, celebrado en Las Palmas de Gran Canaria, presentamos un trabajo (pendiente de publicación) en el que hablamos de esta cuestión (Sosa-Alonso, 2020), en la que parece ser que los espacios vinculados a los moriscos 
tienen relación con la presencia de cruces grabadas o como el caso que nos ocupa, pintada. Quizá estas poblaciones debían dejar claro que practicaban el cristianismo en un momento de la historia en el que la religión era de suma importancia y debieron de buscar formas de integrarse en la nueva sociedad colonial usando como vehículo las representaciones rupestres de cruces.

Lo que sí está claro es que las pinturas son diferentes entre sí y, de momento, ninguna de estas figuras humanas se puede vincular con grafismos alfabéticos a diferencia de los grabados. Este dato es importante, pues nos hace pensar que dichas figuras no se pintaron a comienzos de la primera colonización humana de la isla. Sin embargo, queda mucho por hacer como la recogida de muestras de pigmentos para datar y conocer los componentes reales o la excavación arqueológica de estos enclaves cuya aportación nos ayudaría a entender en mejor medida el contexto de estos espacios. Pero también sería interesante estudiar con detalle cada pigmento a través de herramientas que no tenemos a día de hoy a

\section{Bibliografía}

Batllori y Lorenzo, J. (1900): "Mi última tentativa: La Cueva Pintada”. El Museo Canario, 9: II7-I23. Beltrán Martínez, A. (1971): Los grabados rupestres del Barranco de Balos. CSIC. Las Palmas de Gran Canaria.

Beltrán Martínez, A. y Alzola González,J.M. (1974): La Cueva Pintada de Gáldar. Talleres Editoriales «Librería General». Zaragoza.

CAMC. (I974): "Inventario de yacimientos rupestres de Gran Canaria”. El Museo Canario, 35: 199-226.

Cuenca Sanabria, J. (1992): "Nueva estación de grabados alfabetiformes en el Roque Bentayga". El Museo Canario, 49: IoI.

Cuenca Sanabria,J. (I995): "Nueva estación de grabados de tipo líbico-bereber en el Roque Bentayga, Gran Canaria”. El Museo Canario, 50: IoI.

Cuenca Sanabria, J. (1997): "La Estela de Gamona”. El Museo Canario, 52: Iог. nuestro alcance, como un espacio especializado en el análisis de micromuestras de los pigmentos y otros elementos de los paneles, pues todo apunta a la existencia de superposiciones que nos cuestan identificar por el momento.

De cara al futuro, los objetivos del trabajo en la pintura rupestre de Gran Canaria irán encaminados a la recogida de micromuestras con un bisturí esterilizado, que con unos poco miligramos podremos obtener más información de las mismas. Sería interesante localizar estratos de organismos como hongos o líquenes en estratos inferiores y superiores a las pinturas para realizar dataciones y tener una estimación de la fecha en que fueron ejecutadas. Aparte de ello, se podrá también analizar los componentes físico-químicos de los pigmentos, lo cual nos dará muchas pistas de como se preparaba la pintura, si hay componentes orgánicos o no en ellas, etc. Pero para ello precisamos de un equipo multidisciplinar que nos proporcione el conocimiento y las herramientas necesarias que ayuden a la reconstrucción histórica del uso de las pinturas en los abrigos y cuevas de la isla de Gran Canaria.

Cuenca Sanabria, J. (1996): "Las manifestaciones rupestres de Gran Canaria”. Manifestaciones rupestres de las islas Canarias. Dirección General de Patrimonio Histórico, Viceconsejería de Cultura y Deportes, Gobierno de Canarias. Las Palmas de Gran Canaria: $133^{-222 .}$

Cuenca Sanabria, J., Martínez Torcal, M., Montelongo, J. y Ramos Díaz, P. (2004): "Nuevas aportaciones al corpus de grabados rupestres de Gran Canaria: las estaciones del Morrete de las Chocillas y Barranquillo del Cardón”. XVI Coloquio de Historia Canario Americana. Cabildo Insular de Gran Canaria. Las Palmas de Gran Canaria: $36 \mathrm{I}-387$.

Cuenca Sanabria, J., García Navarro, M., González Arratia, L. y Montelongo, J. (2008): "El culto a las cuevas entre los aborígenes canarios: el almogarén de Risco Caído". Almogaren, 39: I53-19o.

Grau Bassas, V. (1882): "Inscripciones numídicas de la isla del Hierro". El Museo Canario, 5: 265-267. 
Harman, J. (2008) [2005]: Using Decorrelation Stretch to Enhance Rock Art Images. <http:// www.dstretch.com/AlgorithmDescription.html>. [Consulta: 20 de mayo de 20I8].

Hernández Benítez, P. (1945): "Inscripciones y grabados rupestres del Barranco de Balos". El Museo Canario, I5: I4.

Hernández Pérez, M. (1973): Grabados rupestres del archipiélago canario. Tesis doctoral inédita. Universidad de La Laguna. La Laguna.

Hernández Pérez, M. (r996a): “Antonio Beltrán Martínez y el arte rupestre del archipiélago canario". Tabona, 15: 19-26.

Hernández Pérez, M.S. (1996b): "Las Manifestaciones rupestres del Archipiélago Canario". En J. Cuenca Sanabria y A. Tejera Gaspar (eds.): Las Manifestaciones rupestres de las Islas Canarias. Dirección. General de Patrimonio Histórico, Viceconsejería de Cultura y Deportes, Gobierno de Canarias. La Laguna-Tenerife: 25-47.

Hernández Rodríguez, N. (1997): El color en las manifestaciones de los antiguos habitantes de las islas Canarias: Las cuevas pintadas de la isla de Gran Canaria. Tesis doctoral. Universidad de La Laguna. La Laguna.

Jiménez Sánchez, S. (1946): "Excavaciones arqueológicas en Gran Canaria, del Plan Nacional de I942, I943 y 1944". Informes y Memorias, II: 34-39.

Jiménez Sánchez, S. (I96I): «Pictogramas antropomorfos de un abrigo pastoril de Majada Alta». Faycan, 8: 3-го.

Jiménez Sánchez, S. (1962): "Nuevas aportaciones al mejor conocimiento de las inscripciones y de los grabados rupestres del Barranco de Balos, en la isla de Gran Canaria”. Anuario de Estudios Atlánticos, 8: 87-39.

Jiménez Sánchez, S. (1962): "Pictogramas antropomorfos de una abrigo pastoril de Majada Alta, Término de Tejeda”. Faycán, 8: 5-ıo.

Jiménez Sánchez, S. (1963): "Pictogramas antropomorfos de la Cueva del Moro, en el Lomo de las Moriscas, en Agaete, isla de Gran Canaria”. Las Palmas de Gran Canaria.

Jiménez Sánchez, S. (I966): "Pinturas rupestres antropomorfas en la isla de Gran Canaria”. V Congreso Panafricano de Prehistoria y Estudio del Cuaternario (Santa Cruz de Tenerife, 1965). Vol. 2. Cabildo Insular de Tenerife. Santa Cruz de Tenerife: I47-I52.
Jiménez Sánchez, S. (I970): "Nuevos pictogramas y grabados parietales del arte rupestre canario, Cueva del Péndulo". Revista de Historia Canaria, 33: 78-84.

Jiménez Sánchez, S. (1970): "Pictogramas antropomorfos de la «Cueva del Moro» en el «Morro de las Moriscas» (Agaete)". Anuario de Estudios Atlánticos, r6: 561-575.

Marchante Ortega, A. (20I6): "Análisis macro y microespacial del abrigo inédito de Puerto Baterno (Agudo, Ciudad Real) y su inserción dentro del arte rupestre esquemático de los Montes de Ciudad Real, Valle de Alcudia y Sierra Madrona". Vinculos de Historia, 5: 16I-195.

Martín De Guzmán, C. (1988): Las culturas prehistóricas de Gran Canaria. Tesis doctoral. Universidad Complutense de Madrid. Madrid.

Martín Rodríguez, E., Miranda Valerón,J.y Velasco Vázquez,J. (1992): "Contribución a la carta rupestre de Gran Canaria. La estación del Barranco de La Sierra (Guayadeque, Gran Canaria)". Vegueta, o: 25-34.

Martín Rodríguez, E. (2002): "El patrimonio rupestre de Gran Canaria. Los grabados de la Montaña de las Vacas (Aldea de San Nicolás)”. Vegueta, 6: 9-20.

Martín Rodríguez, E. et alii (2007): "Nuevas investigaciones en torno a los grabados rupestres del Barranco de Balos (Agüimes, Gran Canaria)". Tabona, 16: 193-218.

Martín Rodríguez, E., Velasco Vázquez,J., González Marrero, M.C. y Ramírez Sánchez, M. (2008): "Nuevas investigaciones en torno a los grabados rupestres del Barranco de Balos (Agüimes, Gran Canaria)". XVII Coloquio de Historia Canario Americana. Cabildo Insular de Gran Canaria. Las Palmas de Gran Canaria.: 347-353.

Naranjo Rodríguez, R. (1983): "Las pinturas rupestres de Majada Alta". Aguayro, 150: 15-17.

Naranjo Rodríguez, R. (1984): "El granero de «Las Moriscas» y sus pinturas antropomorfas". Aguayro, $155: 20-20$

Pereira Uzal, J.M. (2013): "Modelado $3{ }_{3} \mathrm{D}$ en patrimonio por técnicas de structure from motion". PH Investigación: revista del LAPH para la investigación del patrimonio cultural, r: 77. 
Onrubia Pintado, J., Rodríguez Santana, C.G. y Saenz Sagasti, J.I. (2008): “Trogloditismo y patrimonio prehispánico: La musealización de la Zona Arqueológica de la Cueva Pintada, Gáldar, Gran Canaria”. El patrimonio trogloditico de Gran Canaria. [S. I]. Asociación Insular de Desarrollo Rural de Gran Canaria, Aider. Las Palmas de Gran Canaria: 92-97.

Ramírez Sánchez, M. (2000): "Aproximación historiográfica a la investigación arqueológica en $\mathrm{Ca}$ narias: La Comisaría Provincial de Excavaciones arqueológicas de Las Palmas (1940-1969)". $3^{\circ}$ Congresso de Arqueologia Peninsular: Arqueología Peninsular. Histórica, Teoría e Práctica (Vila Real, I999). ADECAP. Porto: 4I7-429.

Sosa-Alonso, P.J. (2018a): "La fotografía antigua como técnica de documentación y registro en el estudio de las manifestaciones rupestres de Gran Canaria". Cartas Diferentes. Revista Canaria de Patrimonio Documental, I4: 303-326.

Sosa-Alonso, P.J. (2019): "Estudio preliminar de análisis de imagen con DStretch sobre los grabados rupestres indígenas e hispano-canarios: el caso del Barranco de Balos en la isla de Gran Canaria". Sociedades prehistóricas y manifestaciones artísticas: imágenes, nuevas propuestas e interpretaciones. Instituto Universitario de Investigación en Arqueología y Patrimonio Histórico (INAPH). Alicante: 279-284.
Sosa-Alonso, P.J.y Babón García, H. (2020): "Contribución al estudio de las manifestaciones rupestres de los antiguos canarios. Documentación y análisis de imagen de la estación de grabados y pinturas de Cuevas de Cubas (Telde, Gran Canaria)". XXIII Coloquio de Historia Canario Americana (20I8). Cabildo Insular de Gran Canaria. Las Palmas de Gran Canaria: I-20

Sosa-Alonso, P.J. (e.p.): "Contexto arqueológico $\mathrm{y}$ arte rupestre. El caso de los petroglifos del Barranco del Draguillo (isla de Gran Canaria)". En E. Acosta Guerrero (ed.): XXIII Coloquio de Historia Canario-Americana. Museo Casa de Colón. (Las Palmas de Gran Canaria, 2020).

Sosa-Alonso, P.J. (e.p.): "Image analysis and treatment for the detection of engravings and its overlays: rediscovering rock art in the Balos ravine (Gran Canaria)". Rock Art Research, 39: I-2I.

Stone, O.M. (1887): Tenerife and Its Six Satellites on the Canary Islands, past and present. II. Marcus Ward \& Co. Limited. London.

Verneau, R. (I882): "Les inscriptions lapidaires de l'Archipiel Canarien". Revue d'Etnographie, 2: 273-287. 